\title{
Extent of Staff Professional Ethical on Customers' Commitment in Hotel Industry: An Empirical Study - Three-star Hotels in Jordan
}

\author{
Nouria Fleah Al-Juboori ${ }^{1}$ \\ ${ }^{1}$ Tourism Management Department, Faculty of Economics and Administrative Sciences, Al-Zaytoonah \\ University, Jordan \\ Correspondence: Nouria Fleah Al-Juboori, Tourism Management Department, Faculty of Economics and \\ Administrative Sciences, Al-Zaytoonah University, Jordan. E-mail: nouria_1983@yahoo.com
}

Received: September 19, 2016

Accepted: October 4, 2016

Online Published: November 8, 2016

doi:10.5539/ibr.v9n12p76

URL: http://dx.doi.org/10.5539/ibr.v9n12p76

\begin{abstract}
The aim of this study is to understand the practical situation of work ethics in hospitality industry organizations in Jordan by focusing on professional ethics in relation to employees and managers. It also focuses on how such professional ethics prevail in hospitality industry facilities and affect customers' commitment. The study used primary data by distributing a questionnaire to staff in three-star hotels. The results revealed a positive relationship between the dependent and independent variables from the staffs' point of view by using simple regression. It is also concluded that professional ethical principles can be applied in hospitality facilities, primarily in dealing with customers and maintaining ethical trust; and that the staff (employees and managers) understands and appreciates the importance of having professional ethics in their organizations, as they lead to customer satisfaction and increases the level of commitment.
\end{abstract}

Keywords: ethical values, professional ethics, hospitality industry

\section{Introduction}

In light of the rapid burst of evolution, the need for determining the basic principles and work ethical concepts emerged to keep up with this development and follow the path of success and profitability. For business, organizations management methods and achievement of continuous success all have an effect on individuals' ethical transformation. This situation has raised numerous questions regarding the extent to which those individuals comprehend such ethics, and whether its application process reflects positively on the organization, or it came for their personal favor in order to assist in achieving individual and targeted profits. This was also reflected on organization interest, which considers customer satisfaction, as they are the true scale of its success and continuity in the sector.

The cornerstone of hospitality industry organizations is based on professional ethics as a basic and long-term strategy to earn customers' trust and to preserve the standards of such professional hospitality organizations, namely, restaurants, entertainment centers, and travel agencies. This is due to the fact that the quality standard of production is achieved by the satisfaction of customers from different ranks and, hence, it sheds light on the importance of determining professional ethics as well as the extent to which the staff's acceptance to maintain and apply these factors. A study of hotels in Australia found that $39.19 \%$ of the managerial staff left within one year indicating a lack of employee's commitment (Davidson et al., 2010). This lack of commitment in hotels may be attributed to low wages, unsocial working hours, low job satisfaction and limited career advancement opportunities (Aksu, 2004). The success of the transaction depends largely on the success of the interaction between the employee and the customer (Ford et al., 2012). While others added that management commitment in hotel settings is vital to individual and organizational outcomes since the success of hotels is largely dependent upon positive interactions between employees and customers (Davidson et al., 2010). Committed individuals, who work harder, are less likely to be absent from work and have fewer intentions to quit their employment, possess increased job satisfaction and have the ability to increase productivity (Patiar \& Wang, 2016). But the question is how employee and management ethical values based on their commitment affect customers' commitment and loyalty toward the hotel industry.

Researchers maintain that the hotel industry has a turnover "culture" existing at both operational and managerial levels (Davidson et al., 2010). The interest of this study was for the purpose of understanding the use of a 
specific work ethic in hospitality industry organizations staff, the acceptability of professional ethics and finding out the extent of their implementation on customers' commitment toward hotel industry.

\section{Research Problem}

Scientific references for this type of study for the hospitality industry in Jordan are limited. Small- and medium-sized enterprises (SMEs), defined as organizations with less than 250 employees (OECD, 2014), have less ability to retain employees than their larger competitors. Large organizations can usually offer better payment and more promising career prospects (Nadin \& Cassell, 2007). This forms a challenge and research problem to seek if there are any professional ethics that are considered as principles, and how do these ethics affect the operating results of the hotels in Jordan and whether customers are satisfied while the organization reaches its targeted profits.

\section{Importance of Study}

The research tries to pinpoint the following points:

1. Identify entrepreneurial staff professional ethics in order to be applied in the hospitality sector facilities which affect product quality in Jordan in general.

2. To identify the difference between employee and management perspectives in order to reduce the gap between the two parties through correcting erroneous paths pursued by management and to enhance principles that help employees compete in order to improve production levels.

3. To find out solutions to research problems, through concluding ethical knowledge applied in the hospitality industry.

\section{Objectives of Study}

This study seeks to achieve the following:

1. Stand on employees' professional ethics and their effect on customers' commitment toward the hotel.

2. Identify the relationship between managers' professional ethics and its effect on the customers' commitment and loyalty toward the hotel.

\section{Hypotheses of the Study}

The hypotheses of this study have been divided to fit study model dimensions as follows:

\section{Main hypothesis:}

There is a statistically significant relationship between hotel staff awareness of ethical concepts and customers' commitment. The main hypothesis was divided into two sub-hypotheses, which are:

H1: There is a significant relationship between employee professional ethics and customers' commitment.

$\mathrm{H} 2$ : There is a significant relationship between managers' professional ethics and customers' commitment.

\section{Literature Review and Theoretical Framework}

Opening opportunities for organizations to deal directly with staff through regular meetings to clarify the importance of implementing business ethics may ease every staff member's task. Some argue that psychological discomfort may be caused due to miscommunication between managers and employees and then cause dissatisfaction of both teams which may eventually affect the customers' commitment toward the institute. However, if each team acts help in raising morals among staff, then this in its turn raises loyalty rates, which may be reflected positively on the customers' commitment. The tension and development of committed, satisfied and motivated employees is vital, as this type of employee is likely to work harder and contribute more to business performance, compared to those who are not very involved in the organization, due to their greater individual effort (Karatepe, 2013). Moreover, it must meet consumer expectations that are constantly developing in regard to the quality of service (Skogland \& Siguaw, 2004). The specific organizational context of development essentially relates to the hotel establishment's strategy, structure, technology, culture and to the characterization of its employees and managers' commitment, competencies and skills (Prud'homme \& Raymond, 2016).

Ethics are defined as disciplines that deal with what is good or bad, duty and commitment (Carroll, 2006), or it is the set of principles, standards and values that enhance individual behavior in different selections (Ghalibi \& Ameri, 2007). While profession ethics or business ethics are the behavior in the business area, they are the total sum of experiences, education, the director rearing or members of project board of directors. Ethics in every society is the product of long historical development and are necessary for society formation, maintaining, and stability (Alake, 2008). The sources of ethics in community are numerous since they come through religious 
beliefs, community's history, experience, cultural national traditions, tribal, clan, family, peers, reference groups, opinion and typical roles, practical experience and learning leaders. It is possible to review these sources as shown in Figure 1 below (Carroll, 2006), which demonstrates all individuals whether managers or employees or officials, and their actions and judgments on their work or their decisions based on their ethical base.

Managers daily face many decisions in addition to employees or customers attitudes that need to be developed properly. Thus, hotels whose general managers are committed to environmental issues are better equipped to develop valuable environmental management capabilities (Hyun et al., 2015). Decisions were taken and including developed policies are in line with norms and proper ethics which lead to increase benefit and achieve organizational goals that can be expressed through dealing with the following questions (Ghalibi \& Ameri, 2007): how an organization treats its employees? How employees treat an organization? And how organization and its staff deal with other parties (consumers, competitors, brokers, suppliers, unions and others)? So the relationship between leadership style and organizational culture suggest that top managers influence firms' business performance through altering or establishing certain shared values and norms (Asree et al., 2010). Managers have a perspective by which they interpret the ethical behavior they depend on in running their business and operational decisions for organization management. This is based on a set of approaches as:

1-Utilitarian approach: The behavior is considered ethical if its outcome is of big benefit, or the benefit could serve a large number of people.

2-Individual approach: ethical behavior is the one that leads to maximizing individual's interest in the long term, and based on that benefit others and help managers in achieving their basic goals.

3- Rights approach: The behavior is deemed ethical if it respects and maintains individuals basic rights and to all those affected by it, so the organization has to take into account the relationship between it and its customers.

4-Justice approach: the ethical behavior is the one based on the others treatment impartially and fairly depending on the rules of law.

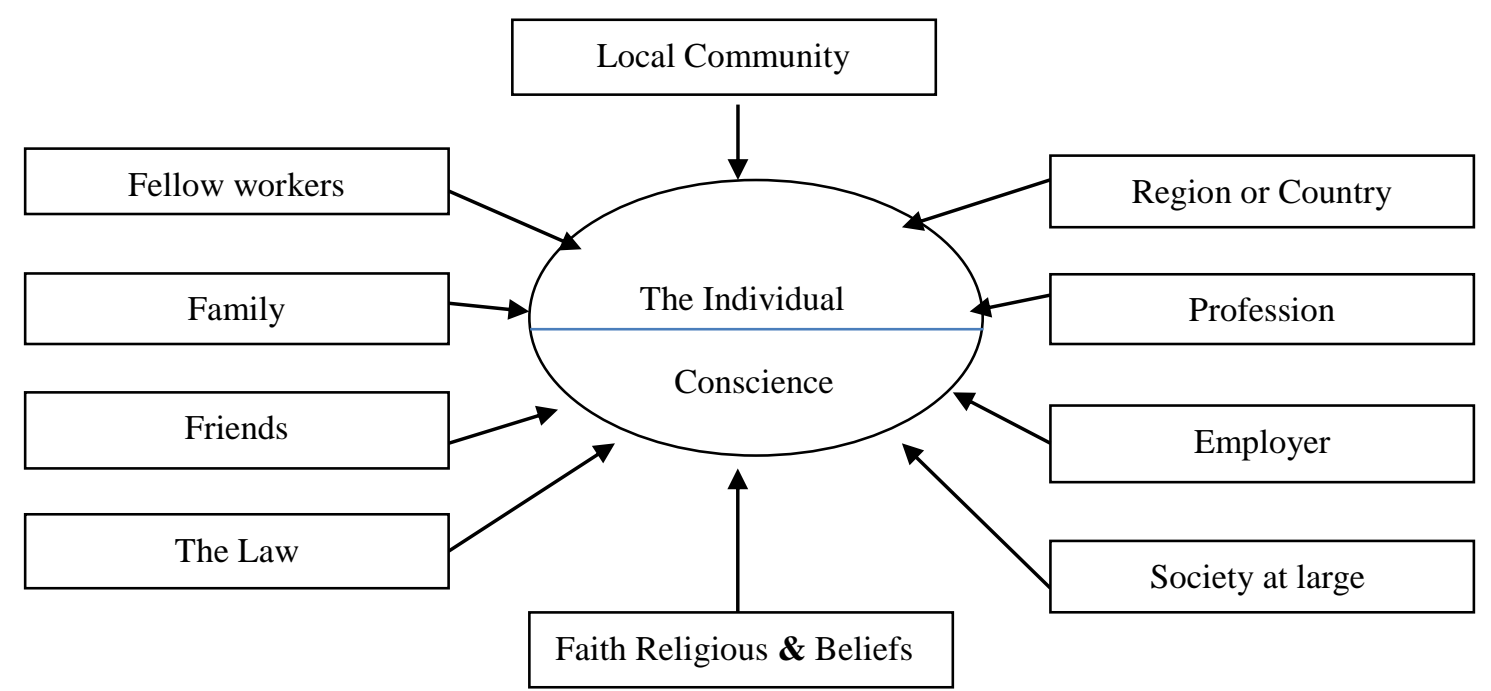

Figure 1. Elements influencing the prevailing norms of ethical behavior as a basis for ethical provisions on business and actions (Carroll, 2006)

It must be mentioned that laws obliged to individuals to comply with is "an important ethical standard", and can lead to the opposite of what they had been enacted. A study by (Najem, 2006) concluded that $20 \%$ of senior management changed their principles and their personal values according to organization expectations, $27 \%$ members of middle management, and $47 \%$ of members of the lower administration. This erosion is due to organizations characteristics upon which organizations are formed or depend on, such as hierarchical authority and rules that identify work and control, which motivate all employees towards unified goals and learn and master to comply with the imposed decisions and actions. These forms of organization and practices generate heavy pressures on managers, employees, customers' principles and personal values. In addition, group management may have a greater impact in reducing managers' engagement in decisions and programs that can be considered the concepts and immoral practices.

Hospitality industry organizations always seek to reach loyal customers because such customers have attitudes 
that drive them to search for safe, valued and quality products, which are obtained from organizations that comply with professional ethics. That, in turn, helps them to provide their product and face competition with others and ensure their market share. World Tourism Organization has issued a set of legislation and legal instructions under the title (Global Code of Ethics for Tourism-translated into Arabic Language) for 1999, confirming their commitment to equality between men and women who are working in this sector and enhancing human rights, and also indicating tourism employees commitment by providing objective and truthful information to tourists. It also suggests that employees with low wages or self-employed in the tourism sector have the right, even the duty, to have adequate social protection, by reducing job insecurity as much as possible.

The major concern of the World Organization for hotels and restaurants is to promote trade profession reputation and level and ethical commitment - behavior of employers as they are a model for their employees (Houri, 2012). Locally there is a great similarity in the hospitality industry between the Arab States, as well as Jordanian Restaurants Association Regulation ensures proper treatment and behavior of various businesses within the hospitality industry and to ensure their commitment to behaviors and ethics in dealing with their customers since they represent the example to the rest of the employees. Some practices lead to positive organizational results by increasing and developing employees' knowledge and skills, and empowering them to make the most of them (Domínguez-Falcón et al., 2016). Governments, organizations and professional associations and unions who represent employers in multi hospitality industry sectors enact laws and develop behavioral rules, regulations and disciplinary regulations to bind those towards the customer (Houri, 2004).

The following are organizational stress types that can be associated in connection with management ethics. The role of staff involvement is highlighted with previous researches as an inseparable part of customer satisfaction and commitment projects (Kale, 2004).

\section{1- Official Rule Pressures}

Procedures and working methods are set to determine what is needed and what may be reduced to differentiate between individuals and environments due to the unification of what must be done based on the organization's perspective. So these rules become the alternative to individual values, which expose them to ethical pressures known as what is right, but fail to do because of the pressure rules.

\section{2- Manager Pressure}

If managers' pressure was to pass illegal attitudes and actions, it is deemed immoral by the boss since it represents an extortion or damage threat. The acceptance of this pressure is also considered immoral by the subordinate since it is deemed as a bribe to the boss. It is assumed that a manager should embrace competencies irrespective of differences that exist between job applicants and within the organization's needs as long as these individuals have the ability of outstanding and performance in jobs they occupy. Mangers' practice of equal opportunity and non-extremism or discrimination principals are is matters stated by law. But conviction must be generated among these managers and then translated to them in the workplace, as distinction here, is due to race or beliefs, nationality, religion, group or any other difference.

Group work has many values and benefits since it increases individuals' norms and ethical values promoted to their counterparts' level, and the emergence of group standards and ethical values as a result of the interaction, teamwork and team spirit (Najem, 2006). Also, industrial, commercial or service processes complexity make them out of any single person capabilities. The only effective way to deal with problems or to improve current business is to depend on a group or team that provides its members with decision-making participation, information consultation and coordination process improvement between various functional areas and to build confidence and create good relations among the staff and the customers (Isa and Al-Tai, 2008).

\section{Research Method}

\subsection{Methodology}

The research was carried out by primary data, collected by using a structured questionnaire. The questionnaire was divided into (4) groups. The first group was related to personal information of the study sample, while the second group consisted (6) statements that serve the first dimension in relation to professional ethics and customers' commitment. The third group consisted (8) statements regarding professional ethics related to employees treatment. Finally, the fourth group (6) statements directed toward professional ethics and managerial process officials. The data were analyzed by using data statistical analysis through using SPSS statistical 22 software. 


\subsection{Sample and Statistical Population}

The statistical population in this study included staff members in three-star hotels (managers and employees). The questionnaire was distributed among 140 participants, and 124 were recollected, of $88.6 \%$.

\section{Measurement}

The measurement of this research is depending on two type of variable which are dependent variable and independent variable. Customers' commitment is the dependent variable while employee and managers professional ethics are the independent variables. For the measurement of this variable, the research constructed a questionnaire, based on previous studies and the researchers' practical experience in hospitality industry.

\subsection{Dependent Variable}

\section{- 8.1.1 Customers' Commitment}

Customers may become narrow-minded and short - sighted if the relationship with the organization is restricted to what is obtained compared with the amount paid for it. Customers' commitment in light of this relationship may mean that customers placing additional and ethical demands are in the forefront (Najem, 2006). Commitment to business ethics is a reflection of trust, transparency and credibility requirements that confirm to avoid all forms of fraud, corruption and unethical practices (Kafi, 2014). As for organizations dealing with other parties such as suppliers, brokers and trade unions, it is outside the research framework, where the focus is on ethical - professional relationships between departments and employees and how they deal with these customers. Customer relationship management $(\mathrm{CRM})$ in hotels has a strong effect on identifying and retaining the most profitable guests; and improving the commitment and loyalty of new guests (Wang, 2012).

\subsection{Independent Variables}

\section{- 8.2.1 Employees Professional Ethics}

The creating key of an organization's competitive advantage is directly based on respecting its members' diversity and allowing each of them to utilize his capabilities and skills to the maximum. This encourages employees to follow positive behavior and perseverance in creative work and commitment to main supreme interests of organizations (Ghalibi \& Ameri, 2007). Despite that, individuals may possess such compliance and commitment to public standards (laws and principles and ethical standards), as the one group member finds due to the interconnection between group members and group common standards.

\section{- 8.2.2 Managers Professional Ethics}

Managers are individuals who have a significant impact on subordinates, due to position powers. Because of unequal status and power between the two, there is a need to settle that through one option, which is either the subordinate agrees with the manager or rejects and leaves. Some research indicated that employees working for transformational leaders are more innovative and direct their energy toward the benefit of the organization (Xenikou \& Simosi, 2006). Demonstrating transformational leadership behavior can be successful (Mesu et al., 2015) and lead to higher customer commitment.

\section{Data Analysis \& Results Discussion}

The reliability coefficient presented by alpha showed a degree of $86.7 \%$, which is relatively high and accepted for scientific research, and gives a good indication on the formulation of the research tool, accuracy, and consistency of the objectives of the study, which enhances the reliability of the results.

\subsection{Descriptive Statistic Results}

\subsubsection{Demographical Results}

Table 1 indicated that majority of employee's who are working in three stars hotel are males where their percent is $85 \%$ of the total sample. $69 \%$ of the samples ages were ranged between $20-30$ years, $28 \%$ were between $31-40$ years. In regard to the education level, $38 \%$ of the study sample had a secondary school degree, and $34 \%$ of the sample had a diploma, while $26 \%$ were bachelor's degree holders and $2 \%$ were master's degree holders. It is worth mentioning that such type of hotels and due to services nature, do not need staff with higher education levels. As for years of experience the sample majority had less than 5 years' experience that is $47 \%$, while $35 \%$ had an experience period from 6 to 10 years, and $11 \%$ had an 11 to 15 years' experience. In terms of monthly income, 55\% of the samples income was less than $200 \mathrm{JD}$, while 26\% have a monthly income for 201-400 JD, and 19\% of the samples income ranged between 401-600 JD. None of the sample's subjects have more than the mentioned levels of monthly income. 
Table 1. Sample distribution according to Demographic information

\begin{tabular}{|c|c|c|}
\hline Variable & Frequency & Percentage \% \\
\hline \multicolumn{3}{|l|}{ Gender } \\
\hline Male & 106 & $\% 85$ \\
\hline Female & 18 & $\% 15$ \\
\hline \multicolumn{3}{|l|}{ Age } \\
\hline 20-30 years & 86 & $\% 69$ \\
\hline $31-40$ & 34 & $\% 28$ \\
\hline $41-50$ & 4 & $\% 3$ \\
\hline \multicolumn{3}{|l|}{ Educational level } \\
\hline High School & 48 & $\% 38$ \\
\hline Diploma & 42 & $\% 34$ \\
\hline Bachelor & 32 & $\% 26$ \\
\hline Master & 2 & $\% 2$ \\
\hline \multicolumn{3}{|l|}{ Years of experience } \\
\hline Less than 5 years & 58 & $\% 47$ \\
\hline 6 - to 10 years & 44 & $\% 35$ \\
\hline 11 to 15 years & 14 & $\% 11$ \\
\hline 16 years and above & 8 & $\% 7$ \\
\hline \multicolumn{3}{|l|}{ Monthly Income } \\
\hline Less than $200 \mathrm{JD}$ & 68 & $\% 55$ \\
\hline $201-400$ & 32 & $\% 26$ \\
\hline $401-600$ & 24 & $\% 19$ \\
\hline Total & 124 & $100 \%$ \\
\hline
\end{tabular}

Based on the analysis, it can be concluded that employees were youth and those whom their age ranged between 20-30 years, the majority were males, their salaries were less than $200 \mathrm{JD}$, and they have secondary school or diploma and most of them are at the beginning of the job ladder and have limited experience. Thus the results revealed that employees in the hotels are youth, mature and capable of providing service with high levels, and it could be understood from another aspect that three stars hotels are a link or stage in which employees are developed to move to four or five stars hotels.

\subsubsection{Pearson Correlation}

Pearson correlation is used to answer such a question as in table 2, and for scientific research a correlation of 0.643 and 0.531 for both types of independent variables, namely employee ethics and management ethics, respectively, Results showed a strong relationship between the client commitment and independent variables, as correlation appeared at a level of 0.056 significance, for employee ethics and 0.003 significance for the management ethics.

Table 2. Pearson Correlation

\begin{tabular}{lclll}
\hline & & AVGCom & AVGEMP & AvgMANG \\
\hline AVGCom & Pearson correlation & 1 & & \\
& Sig. (2-tailed) & & & \\
AVGEMP & N & 124 & 1 & \\
& Pearson correlation & $.643^{* *}$ & & \\
AvgMANG & Sig. (2-tailed) & .056 & 120 & 1 \\
& N & 124 & $562 *$ & 124 \\
& Pearson correlation & $531^{*}$ & .001 & 124 \\
\hline
\end{tabular}

* Significant at a level of 0.01 .

**Significant at a level of 0.05 .

9.1.3 Mean and Standard Deviation for Different Factors Expected to Affect Clients' Commitment in Relation to Employees and Management Professional Ethics

The descriptive statistics of all questions investigated in this study were illustrated in table 3 (mean and standard deviation). Using data from 20 observations, the analysis of the sample study also shows that the employee professional ethics were found to have a mean of 3.96, while 4.08 were for the management professional ethics. It was also proven that the customers' commitment had a mean of 4.1 . 
Table 3. Means and standard deviations of sample's responses

\begin{tabular}{|c|c|c|c|}
\hline No & Question & Mean & S.D. \\
\hline \multicolumn{4}{|c|}{ Customer commitment } \\
\hline 1 & $\begin{array}{l}\text { Dealing with customer attitude as imposed by profession ethical concept causes employees } \\
\text { self-conflict }\end{array}$ & 3.23 & 1.06 \\
\hline 2 & Many professional ethic principles approved an action plan that helped to gain customers commitment & 4.18 & 0.74 \\
\hline 3 & Due to principle "achieving profit" customers are given improper information & 4.29 & 1.18 \\
\hline 4 & $\begin{array}{l}\text { Big distinction in customer's treatment, based on personal interest of managerial official not by order } \\
\text { of importance. }\end{array}$ & 4.61 & 1.11 \\
\hline 5 & Kindness to deal with customer is basic in gaining customer satisfaction and commitment & 4.50 & 0.74 \\
\hline 6 & Managers follow the principle of "customer is always right even if not" & 3.81 & 1.16 \\
\hline \multicolumn{2}{|r|}{ Total } & \multicolumn{2}{|l|}{4.103} \\
\hline \multicolumn{4}{|c|}{ Employee professional ethics } \\
\hline 7 & Rewards and bonuses are granted to hard working employ & 3.73 & 0.79 \\
\hline 8 & Punishment methods are based on the size of default & 3.71 & 0.82 \\
\hline 9 & Personal relationship exempts employee from many punishments & 4.06 & 1.27 \\
\hline 10 & Service rewards granted to all staff are systematically fair & 4.19 & 1.01 \\
\hline 11 & Employees are appointed to personal relationships & 4 & 1.40 \\
\hline 12 & Rewards and money incentives are granted for men more than women & 4.03 & 0.90 \\
\hline 13 & Discrimination of gender, not on efficiency and qualifications & 4.11 & 1.06 \\
\hline 14 & Females are excluded from positions that affect work decisions & 3.84 & 1.23 \\
\hline \multicolumn{2}{|r|}{ Total } & \multicolumn{2}{|l|}{3.958} \\
\hline \multicolumn{4}{|c|}{ Management professional ethics } \\
\hline 15 & The aim of the job is to obtain experience & 4.34 & 1.20 \\
\hline 16 & Organization is considered a lifetime job & 4.40 & 1.05 \\
\hline 17 & $\begin{array}{l}\text { Managers create a work atmosphere that gives employees a sense of cooperation, intimacy and } \\
\text { equality }\end{array}$ & 3.86 & 1.11 \\
\hline 18 & Managers work to build one teamwork principle within employee's behavioral morals. & 3.73 & 1.10 \\
\hline 19 & Managers are obliged to follow professional ethics that cause comfort to customers & 4.27 & 1.06 \\
\hline \multirow{2}{*}{\multicolumn{2}{|c|}{$\begin{array}{l}\text { Implementation of professional ethics causes a conflict between employees, managers and customers } \\
\text { Total }\end{array}$}} & 4.11 & 1.12 \\
\hline & & 4.1183 & \\
\hline
\end{tabular}

9.2 Hypotheses Testing

The model hypotheses testing results show that the variables of mission; employee and management professional ethics (the independent variables) jointly explain $53 \%$ of the variance (R2) of customers' commitment. As F-value $=60.346$ with $\mathrm{p}<05$, it can be said that the model has a good fit for the data. As shown, there is a significant relationship between the dependent and independent variables; hence, $\mathrm{H} 1$ and $\mathrm{H} 2$ were accepted. The results show that staff professional ethics (both employees and managers) is positively correlated with customers' commitment, and could be depended on, all as indicated in table 4.

Table 4. Hypotheses Test

\begin{tabular}{lcclc}
\hline & \multicolumn{2}{c}{ Dependent variable(Customers Commitment) } & & \\
\hline Independent variables & Beta & t-value & Sig & Adaptability \\
Employee professional ethics & 0.174 & 1.090 & $0.036^{* *}$ & Supported \\
Management professional ethics & 0.178 & 2.405 & $0.007^{*}$ & Supported \\
\hline Multiple $\mathrm{R}=0.73$ & Standard & & $\mathrm{R}^{2}=0.53$ \\
Adjusted & & & $\mathrm{p}<0.001$ \\
$\mathrm{~F}=60.346$ & Error $=0.3125$ & & \\
$\mathrm{R}^{2}=0.52$ & & & \\
\hline
\end{tabular}

Note. * Significant at a level of 0.01 .

**Significant at a level of 0.05 .

\section{Summary and Conclusion}

Based on the descriptive results, most of the three-star hotel employees are males, their age ranged between 20-30 years; their monthly rate is less than 200 JD. Most of the staff were high school or diploma educated, most of them have less than 5 years' experience this is due to the fact that most of the employees leave the work in this type of hotels and move to higher level hotels where wages are more suitable with their experience. While the main purpose of the study was to explore the relationship between employee and managers professional ethics on the customers' commitment, in terms of the three-star hospitality sector in Jordan, results showed a positive effect of the professional ethics on the customers' commitment to a positive significant relationship. For the higher the ethics are, the level of commitment is expected to be higher. Since managers have their perspectives, they should create competitive advantage in their organization, by respecting its members', diversity and allow each of them to utilize their capabilities and skills to the maximum limits. Sign long-term contracts with 
employees', diversification and increasing objectivity and real rewards to comply and to convince employees to stay in the same organization, this may push employees in return to follow positive behavior and perseverance in creative work and commitment to supreme interests of the main organization, where they are to maximize the excellence of performance, innovation and social responsibility, integrity, trust and protect work secrets and adopt teamwork style.

\section{Recommendations and Limitations}

The target of this paper was to explore the relationship between employee and managers professional ethics with customers' commitment. It is recommended to adopt the study on higher star hotels, as they are expected to be more professional and may reveal other results. Future research may pinpoint the weakness in the ethical professional standards in relation to effort and work quality, to increase three-star effectiveness in the industry. Results may not represent the whole population of staff, because in Jordan it is very hard to directly contact them, especially the managers that may be a limitation. In addition, this research was cross-sectional; nothing definite can be concluded concerning causal relationships as by conducting longitudinal studies.

\section{References}

Aksu, A. A. (2004). Turnover costs: research among five-star hotels in the city of Antalya, Turkey. Tourism Analysis, 9(3), 207-217. http://dx.doi.org/10.3727/1083542042781230

Alake, B. (2008). New Management: theories and concepts. Dar Al-Yazouri, Amman, Jordan.

Asree, S., Zain, M., \& Razalli, M. R. (2010). Influence of leadership competency and organizational culture on responsiveness and performance of firms. International Journal of Contemporary Hospitality Management, 22(4), 500-516. http://dx.doi.org/10.1108/09596111011042712

Carroll, A. B., \& Bocholt, A. K. (2006). Business and Society Ethics and Stakeholder Management. South Western. Thomson. U.S.A.

Davidson, M. C. G., Timo, N., \& Wang, Y. (2010). How much does labour turnover cost? A case study of Australian Four- and Five-star hotels. International Journal of Contemporary Hospitality Management, 22(4), 451-466. http://dx.doi.org/10.1108/09596111011042686

Domínguez-Falcón, C., Martín-Santana, J., \& De Saá-Pérez, P. (2016). Human resources management and performance in the hotel industry. International Journal of Contemporary Hospitality Management, 28(3), 490-515. http://dx.doi.org/10.1108/IJCHM-08-2014-0386

Ford, R. C., Sturman, M. C., \& Heaton, C. P. (2012). Managing Quality Service in Hospitality: How Organizations Achieve Excellence in the Guest Experience. Delmar, Cengage Learning, Clifton Park, NY.

Ghalibi, T. M., \& Ameri S. M. (2007), Business and Administration Dar Wael, Amman, Jordan. PMCid: PMC2266966

Ghalibi, T. M., \& Ameri, S. M. (2005). Social Responsibility and Business Ethics. Business and Community. Dar Wael for publication, Jordan.

Houri, M. T. (2012). Legislation and professional organizations in hospitality industry. Unpublished manuscript Amman, Jordan.

Houri, M. T. (2004). Legal relations in hospitality industry. Unpublished manuscript, Amman, Jordan.

Hyun J. K., Jeongdoo, P., \& Wen, J. (2015). General managers' environmental commitment and environmental involvement of lodging companies. International Journal of Contemporary Hospitality Management, 27(7), 1499-1519. http://dx.doi.org/10.1108/IJCHM-01-2014-0011

Issa, K., \& Abdullah, A. R. (2008). Total Quality Management, Dar Yazouri, Jordan.

Kafi, M. Y. (2014). Ethics of Tourism and Hospitality Industry, Dar Rowad, Amman, Jordan.

Kale, S. (2004). CRM failure and the seven deadly sins. Marketing Management Journal, 13(5), 42-46.

Karatepe, O. M. (2013). Perceptions of organizational politics and hotel employee outcomes: the mediating role of work engagement. International Journal of Contemporary Hospitality Management, 25(1), 82-104. http://dx.doi.org/10.1108/09596111311290237

Mesu, J., Sanders, K., \& Van Riemsdijk, K. (2015). Transformational leadership and organizational commitment in manufacturing and service small to medium-sized enterprises. Personnel Review, 44(6), 970-990. http://dx.doi.org/10.1108/PR-01-2014-0020 
Nadin, S., \& Cassell, C. (2007). New deal for old? Exploring the psychological contract in a small firm environment. International Small Business Journal, 25(4), 417-443. http://dx.doi.org/10.1177/0266242607078587

Najem, A. N. (2006). Management Ethics and Business Responsibility in Business Firms. Dar Warraq. Amman, Jordan. PMCid:PMC1885132

OECD. (2014). Small and medium-sized enterprises. Available at: http://stats.oecd.org/glossary/detail.asp?ID1/43123. http://dx.doi.org/10.1787/factbook-2014-20-en

Patiar, A., \& Wang, Y. (2016). The effects of transformational leadership and organizational commitment on hotel departmental performance. International Journal of Contemporary Hospitality Management, 28(3), 586-608. http://dx.doi.org/10.1108/IJCHM-01-2014-0050.

Prud'homme, B., \& Raymond, L. (2016). Implementation of sustainable development practices in the hospitality industry. International Journal of Contemporary Hospitality Management, 28(3), 609-639. http://dx.doi.org/10.1108/IJCHM-12-2014-0629

Skogland, I., \& Siguaw, J. A. (2004). Are your satisfied customers loyal? Cornell Hotel and Restaurant Administration Quarterly, 45(3), 221-234. http://dx.doi.org/10.1177/0010880404265231

Wang, X. L. (2012). Relationship or revenue: potential management conflicts between customer relationship management and hotel revenue management. International Journal of Hospitality Management, 31(3), 864-874. http://dx.doi.org/10.1016/j.ijhm.2011.10.005

World Tourism Organization. (1999). International Code of Ethics for Tourism (10.01.1999), Madrid, Spain.

Xenikou, A., \& Simosi, M. (2006). Organizational culture and transformational leadership as predictors of business unit performance. Journal of Managerial Psychology, 21(6), 566-579. http://dx.doi.org/10.1108/02683940610684409

\section{Copyrights}

Copyright for this article is retained by the author(s), with first publication rights granted to the journal.

This is an open-access article distributed under the terms and conditions of the Creative Commons Attribution license (http://creativecommons.org/licenses/by/4.0/). 